\title{
Da última onda de integração infraestrutural no continente sul-americano: um balanço conciso
}

\section{Daniel Chaves $^{1}$}

\begin{abstract}
RESUMO: Neste texto sobre o debate de escopo mais amplo da Integração Regional Sulamericana, pretende-se ofertar uma breve e concisa apreciação acerca do passo contextual do início de século, a respeito dos projetos e das possibilidades de integração através da infraestrutura energética e rodoviária do subcontinente em seu período pré-crise financeira internacional (2002-2012). Notamos a vitalidade da política externa brasileira sobre a região especialmente após as contribuições dos governos brasileiros do período nas suas regularidades e descontinuidades.
\end{abstract}

Palavras chave: Integração Regional; Infraestrutura; América do Sul

Latest wave of infrastructural integration in the South America: a concise balance ABSTRACT: In this text on the broader debate of the South American Regional Integration, it is intended to offer a brief and concise appreciation of the contextual step of the beginning of the century, regarding the projects and possibilities of integration through the energy infrastructure and subcontinent in its pre-crisis international financial period (2002-2012). We note the vitality of Brazilian foreign policy over the region especially after the contributions of the Brazilian governments of the period in their regularities and discontinuities.

Keywords: Regional Integration; Infrastructure; South America

${ }^{1}$ Niterói, RJ, 1983. Professor adjunto de História Contemporânea na Universidade Federal do Amapá (Unifap). Doutor em História Comparada pelo Programa de Pós-Graduação em História Comparada (PPGHC/UFRJ), docente permanente dos Programas de Pós-Graduação em Desenvolvimento Regional (PPGMDR) e Propriedade Intelectual e Transferência de Tecnologia para a Inovação (ProfNIT/CAPES), sendo deste último, Coordenador do Ponto Focal da Unifap. Vice-Coordenador da Regional Norte da Associação Fórum de Gestores de Inovação e Transferência de Tecnologia (FORTEC). Láurea João Florentino Meira de Vasconcelos de Inovação, da Academia Nacional de Farmácia (2017). Pesquisador Visitante no Centro de Estudos Sociais/Faculdade de Economia da Universidade de Coimbra (CES-FE/UC, 2016-2017). Pesquisa estratégias de Inovação para o Desenvolvimento Regional; Transferência de Conhecimento e Tecnologia em Políticas Públicas; Subalternidades, Emancipações e semânticas políticas. Usa assinar Daniel Chaves. Contato: daniel.chaves@unifap.br e daniel.s.chaves@gmail.com

\section{APRESENTAÇÃO AOS INTUITOS DE INTE- GRAÇÃO DE UMA ÉPOCA}

Com a clara imperiosidade de um olhar brasileiro, respeitaremos a condição sine qua non do Brasil como o ator regional de maior proeminência econômica, geográfica, política e em diversos âmbitos na América do Sul. Antes disso, no entanto, devemos situar a respeito do tema das relações internacionais brasileiras, com forte ênfase na nossa plataforma subcontinental e avançando na direção de uma caracterização da relação entre energia, rodovia e integração regional. Com base nos dados para consulta pública, buscaremos uma elencagem objetiva e compreensiva dos resultados, estru- 
turações e subdivisões das iniciativas multilaterais ora em curso, discutindo inclusive a sua persistência e validade heurística.

O Brasil encontrava-se diante de diversos desafios nacionais estratégicos no início do nosso atual século. A saber: superar o desemprego em massa; alcançar melhorias na educação fundamental, média e superior, atualmente deficitárias; demover a vigente prática de desrespeito contínuo e institucionalizado aos direitos humanos; equacionar a defasagem tecnológica, investindo em Ciência, Tecnológica e Inovação; trabalhar pela preservação da Amazônia e do meio ambiente como riqueza nacional; discutir o inanismo subdesenvolvimentista que hoje nos faz insensíveis sobre os matizes culturais genuinamente brasileiros, em privilégio de indústria cultural estrangeira; efetivar a inserção do Brasil em cúpulas decisórias e em espaços de solução de controvérsias no nível regional e internacional; articular manutenção da soberania nacional, e, não menos importante, dar ênfase ao entorno estratégico geográfico da América do Sul através do fortalecimento do bloco regional ${ }^{2}$.

\section{O QUADRO GERAL DE INSTRUMENTALI- ZAÇÃO DA INTEGRAÇÃO}

Os projetos regionalização do espaço subcontinental sul-americano se tornaram

\footnotetext{
${ }^{2}$ Ver mais em GUIMARÃES, Samuel Pinheiro. Desafios Brasileiros na Era dos Gigantes. Rio de Janeiro: Contraponto, 2006; especificamente sobre a questão cidadã no âmbito sul-americano, ver: SANTORO, Mauricio. Políticas Públicas de Juventude no MERCOSUL. Observatório Político Sul-Americano, v. 10, p. 1-18, 2008.MEDEIROS, Sabrina \& BUARQUE DE HOLLANDA, Cristina. Política Externa e América Latina - Avaliando a Trajetória e Extensão do seu Globalismo e Regionalização. In: TEIXEIRA DA SILVA, Francisco Carlos \& COSTA, Darc. Mundo Latino e Mundialização. Rio de Janeiro: Mauad, 2004.
}

um imperativo para a Política Externa Brasileira em diversas análises, desde as mais comuns questões discutidas ao passo dos dez anos em questão (2002-2012), de maneira especial afirmado nas diretrizes estabelecidas durante os oito anos de governo Luis Inácio Lula da Silva (2003-2010). Ainda, é preciso frisar que para seus vizinhos, esta dimensão também se tornou irremediável e incontornável no passar do alvorecer do Século XXI. No período em questão, caracterizado por turbulências na contestação da ordem global cristalizada na Pax Americana ${ }^{3}$ - do 11 de Setembro às guerras da Era Bush II no Iraque e Afeganistão, com consequente endividamento estadunidense que contribuiu para a Crise Financeira de 2008 notou-se o aprofundamento radical desta estratégia de consolidação da presença brasileira no mundo a partir da plataforma continental sul-americana. No momento assinalado e fundacional tornou-se claro que o Mercado Comum do Sul (MERCOSUL) e a União das Nações Sul-Americanas (UNASUL) compunham os pilares fundamentais deste processo, até hoje resistentes para a compreensão brasileira neste sentido.

Em objetivos francos, reconheceram-se as potencialidades para acelerar a integração a partir da expansão dos mercados nacionais em curso, da capacidade produtiva no campo, da sua estabilidade democrática constitucionalmente assegurada e da nossa questão fundamental: a potencial autossu-

\footnotetext{
${ }^{3}$ Sobre a ideia e o debate em torno do conceito de Pax Americana, ver os trabalhos sobre a ordem mundial comparada, empreendidos nos esforços de Alexander Zhebit e seus colaboradores na segunda metade da década de '00. Sugere-se a consulta a ZHEBIT, Alexander (org.). Ordens e Pacis: abordagem comparativa das relações internacionais. Rio de Janeiro: Mauad, 2011.
} 
ficiência energética ${ }^{4}$. Na esteira deste processo, mais amplo que apenas os últimos dez anos, a assinatura do Tratado Constitutivo da UNASUL em maio de 2008 assim afirmaria a ambiciosa síntese do processo de integração cujo cume teria sido alcançado com a formação de um grande projeto de regionalização capaz de abarcar todos os países netamente sul-americanos, independentes e interessados na convergência de interesses mais diversos. A Cúpula da América Latina e do Caribe, realizada no mesmo ano de 2008 na Costa do Sauípe, Bahia afirmou-se como a inédita ocasião do encontro entre estadistas sem a intromissão ou presença estadunidense ou estrangeira. Tratava-se, a rigor, do clímax de um projeto cujas idas e vindas já haviam sido dadas em um longo percurso desde os primeiros intentos do início do Século XX, consideravelmente acelerados a partir da década de '70, quando a integração energética do Brasil com seus vizinhos teve determinante papel para a integração política. Com o objetivo de securitizar o abastecimento energético e, no limiar do horizonte, para a tão estimada autossuficiência energética com vistas ao fim da dependência frente a outras regiões - com isso, poderíamos dizer com segurança, superar-se-ia a condição dependente do subcontinente frente a outras regiões e grandes potências e, encorajadamente otimista, o estado de atraso econômico ${ }^{5}$. Geoestrategicamente distante

${ }^{4}$ MINISTÉRIO DAS RELAÇÕES EXTERIORES. Balanço de Política Externa 2003-2010. Disponível em: <http://www.itamaraty.gov.br/temas/balanco-depolitica-externa-2003-2010/1.1.3-america-do-sulintegracao-sul-americana>. Acesso em 10 abr. 2012

${ }^{5}$ DE OLIVEIRA, Adilson. Integración y transición energética: una perspectiva brasileña. In: Foreign Affairs: Latinoamérica, ISSN 1665-1707, Vol. 9, №. 2, 2009 , págs. 87-97 dos grandes conflitos globais resultantes do mercado petrolífero - cujas crises do último quartel de século inclusive potencializaram a nossa integração como mencionamos - a América do Sul teria, em decorrência, a oportunidade privilegiada de exportar energia, na medida em que conta com amplas reservas de combustíveis fósseis.

Os intentos relevantes em diversidade - $\mathrm{e}$ quiçá em oposição - a serem destacados sobre esta iniciativa devem ser nomeados, evitando aqui negligenciar a totalidade e pluralidade das determinações dos debates da ordem do dia no período. Assim sendo, será necessário frisar e mencionar as críticas das vanguardas, seja com vistas aos problemas ligados às populações originárias/autóctones e suas condições de vida desafiadas pelo desenvolvimento, seja pelas elites produtivas/dirigentes interessadas na maximização da prosperidade no subcontinente. Nesse sentido, é preciso alertar que as tendências do(s) processo(s) coexistentes de regionalização podem ser muitas vezes profundamente contraditórias e até mesmo antagônicas - como o próprio processo globalizatório assim o é.

Iniciemos pela manifestação clara e pontual de três dos mais importantes atores do jogo sul-americano em potencial econômico. No primeiro trimestre de 2011, Chile, Peru, Colômbia e México promoveram uma importante ruptura geoeconômica e forjaram um novo acordo que articula uma nova composição geopolítica para a compreensão dos fluxos econômicos na América do Sul. A declaração de Lima, que se tornou pública em abril deste mesmo ano, cria uma Área de Integração Profunda do Pacífico entre os quatro países, mais o Panamá como observador, surge com o objetivo de facilitar a convergência e consulta mútua 
bilateral, regional e multilateral sobre fluxos de bens e pessoas, bem como concertar mercados e organismos. O início da segunda década do século $X X I$, profundamente coreografada nas suas crises e transbordes, apresenta aspectos multipolares que impossibilitam arranjos geopolíticos e econômicos estáticos e inertes sobre os referenciais do século XX. Assim sendo, nem México pode apoiar-se no NAFTA; nem Colômbia pode mais conformar-se a unitária agenda do Plan Colombia; nem Peru e Chile, países em crescimento e participes da zona do Pacífico, precisam aguardar a melhor definição do modelo de integração regional que Ihes sejam interessantes. O possível deslocamento do centro econômico do mundo para o Oceano Pacífico é uma oportunidade por demais atraente. O potencial da abrangência geográfica em envergadura hemisférica, o somatório do comércio intra-bloco (US\$ 5 bilhões!) e a prerrogativa do livrecomércio com os EUA são pontos notáveis de uma aliança liberal pró-pacífico, fazendo coro ao esperado deslocamento geográfico do centro comercial do globo, com a constante crise européia, a explosão do PIB chinês e a prosperidade do Sudeste Asiático. $O$ acordo surge, não menos importante, após os sucessivos problemas constitutivos sobre a natureza dos acordos comerciais latinoamericanos - da ALADI (Associação LatinoAmericana de Integração) ao MERCOSUL. $\mathrm{Na}$ medida em que se efetivar, as rupturas que a AIP buscou promover eram enormes: potencializar o relacionamento ÁsiaAmérica Latina, ainda pouco explorado, mas desde então significativo com o incremento da presença chinesa e a já histórica relação nipo-latinoamericana, e também projetar uma nova plataforma para o relacionamento também candente com o MERCOSUL, cujo comércio tem $60 \%$ do volume potencial da AIP. Nas suas características fundacionais, a AIP tinha cunho impactante e profundamente transformadora por natureza: a orientação autônoma dos países para um nexo de coesão é desprovida do abrigo imediato de alguma grande potencia regional ou hemisférica, o que está amplamente relacionado ao futuro cenário apolar contemporâneo, por sua vez. Não menos importante, o critério da vizinhança não é determinante para a construção dos foros de conversação na América Latina - acima da prerrogativa identitária ainda existente, ou em menor medida, sobre a sub-regional, surgia o imperativo da competitividade e barganha junto a outros foros e mercados. Juntando quatro países orientados para a economia de mercado e a estabilidade político-institucional liberal, o acordo pode ser interpretado ao mesmo tempo uma ponte com a NAFTA (North American Free Trade Agreement, Área de Livre Comércio NorteAmericana), um contraponto sobre a ALBA (Aliança Bolivariana para os Povos na Nossa América) e a superação da Comunidade Andina de Nações (CAN), consolidando um novo eixo e ambiente de relacionamento regional sul-americano na busca pelo ordenamento ideológico ainda indefinido para a UNASUL (União Sul-Americana de Nações). Com o acordo, a agenda de livre comércio hemisférica ganha ânimo novamente após o fracasso da Área de Livre Comércio para as Américas (ALCA) com o Mercado Integrado Latinoamericano (MILA), que se forjou no mesmo passo do Acordo do Pacífico; no entanto, uma correção para o futuro deve ser frisada. Dos países da AIP, Chile e Peru possuem tratados de livre comércio com os Estados Unidos, mas também com a China, cuja inclinação a investimentos na agora 
estável América Latina é maior após a certificação da instabilidade política norteafricana, as crises da dívida na Europa e os consecutivos conflitos no Oriente Médio. A integração das bolsas de Chile, Colômbia e Peru faz com que o acordo pudesse ser responsável por volumosos US\$ 57 bilhões de dólares em negócios, combinando empresas mineiras, petroleiras e o setor financeiro-comercial, respectivamente.

Como resultado de um passado recente de sofrimento, paúra, pobreza e esquecimento nos para os países mais pobres do continente, notaram-se de forma clara as vozes de oposição à integração como desenvolvimento econômico industrializante e estatista. Historicamente, uma 'onda vermelha' de escolhas democráticas plenas elegeu diversos representantes à esquerda na América do Sul, mais ou menos nacionalistas - o que nos fará deduzir, imediatamente, seu potencial para a crítica à integração pela infraestrutura energética na medida em que tais reservas ou potenciais são impreteríveis ao projeto de retomada do Estado sobre as economias. Entre estes representantes da nova esquerda sulamericana, podemos notar Rafael Correa no Equador, Evo Morales na Bolívia, Fernando Lugo no Paraguai, Ollanta Humala no Peru; todos concentrados em torno de um arco, uma 'coifa' geopolítica situada do noroeste da Amazônia ao Cone Sul, áreas nas quais nosso interesse geoestratégico no desenvolvimento econômico e ampliação da área de alcance logístico são diretos e explícitos.

Nessa 'onda vermelha' emergiu uma intensa retomada da identidade regional originária - leia-se autóctone, nativa, resistente - assumindo francos tons antiimperialistas em uma clara resposta aos extremos dos 'ajustes estruturais' neolibe- rais dos últimos 20 anos. Nesse processo sociopolítico, a maioria democrática elegeu representantes próprios e não seria mais tutelada por instituições, leis e lideranças brancas (ou brancóides), mas legitimamente identificadas e nascidas no seio deste enorme caldeirão cultural, político e societário identificado na sua própria história. $\mathrm{O}$ autóctone assim se emancipa paulatinamente na atualidade da sua busca pelo poder instituído. Evidentemente, deixando de lado formas ocidentalizadas de organização sociopolíticas, como partidos políticos clássicos, verticais e hierarquizados, que em grande medida são incompatíveis com esse mosaico dinâmico - e essa incompatibilidade definiu nossas relações no preciso ponto em que aterrissamos na década passada, em um presente sacudido pela emersão dessas nacionalidades enquanto elementos centrais para a definição do futuro regional, quiçá da Integração Sul-Americana enquanto processo maior. Em corte histórico, as análises futuras realçarão 0 antiimperialismo, nacionalismo pan-andino de esquerda e as questões do desenvolvimento nacional divergente sobre a integração pela energia derivando em mais um comportamento nacional/regional influente $\mathrm{e}$ decisivo sobre um projeto de Integração Sul-Americana, que possivelmente concorre, como dissemos, na esteira do processo de regionalização em curso e historicamente majoritário. É possível nomear episódios onde essa relação se tornou crítica: Petrobrás (Bolívia, 2006), Odebrecht/Furnas (Equador, 2008), brasileiros proprietários de terra no Paraguai, os 'Brasiguaios', além da questão tarifária em Itaipu (Paraguai, 2008).

Neste sentido, é preciso frisar que os episódios equatoriano e boliviano contra empresas brasileiras, movidos pelas chefias do 
executivo nacional, foram notáveis como momentos do ápice de insegurança em torno do processo de integração - argumento fidelizado pelos formadores conservadores de opinião, ainda que muitas vezes de modo acrítico. Era comum, como ainda o é, a alegação de que o Brasil estaria sendo lesado pelos seus vizinhos ao "pagar a conta" da integração em detrimento da sua reputação, desenvolvimento e retorno de investimentos, quase sempre com a razoável sensação de insegurança jurídica ${ }^{6}$. Nas palavras de Adilson de Oliveira, "Para explotar esas oportunidades, es esencial que el desarrollo del mercado energético regional ocurra de forma cooperativa y coordinada. La elaboración de un marco regulatorio que promueva la oferta de seguridad energética y la constitución de un acuerdo regional que ofrezca seguridad jurídica para la inversión es esencial para el éxito de la transición energética de la región." 7 .

\section{A INTEGRAÇÃO EM PERSPECTIVA}

Retomando o debate sobre a integração sul-americana como um projeto total e homogêneo envolvendo todos os Estados, mencionamos, sem erro, que tais visões se condensavam grandes objetivos para a estratégia nacional brasileira revitalizada, na qual configurava como objetivo claro a reversão de parte dos rumos definidos pelos governos dos anos '90, cuja adesão às agendas globalizatórias - a abertura dos mercados brasileiros para o mundo através das privatizações - teriam reduzido a capa-

\footnotetext{
${ }^{6}$ CONSTRUTORA RESSALTA GANHOS COM ANTECIPAÇÃO DA OBRA. Disponível em: <www.revistaprisma.com.br/ novosite/noticia.asp?cod=2613 >. Acesso em 30 jan 2012.

${ }^{7}$ DE OLIVEIRA, 2009, Ibidem, págs. 87-97
}

cidade autônoma do Brasil em se posicionar e defender-se diante das formas, das ameaças e dos regimes supranacionais, que sujeitariam as decisões nacionais a todo tipo de intempérie exógenas, dos grandes e irregulares atores, dos mercados e, cabe dizer com grifo, dos interesses de quaisquer agentes capazes de orientar a geopolítica mundial e/ou regional ${ }^{8}$. Por outro lado, é preciso mencionar, com fundamento na mesma ambiência destas observações, que tal integração regional também avançou sensivelmente em diversos empreendimentos durante esta mesma década de '90 marcada pela hoje tão criticada liberalização das economias nacionais por via das concessões - leia-se privatizações ${ }^{9}$.

É preciso ressaltar, neste mesmo âmbito de debate, a relevância que o pensamento liberal ilustrado nesta década concede a regionalização, entendendo a inexorabilidade - consideravelmente discutível - do processo de erosão do Estado-Nação westfaliano. Cabe mencionar o texto apologético de Kenichi Ohmae, que discutiu o sentido (para ele) possível de um novo mundo, no qual o paradigma fundante e norteador das relações intra e inter estatais destes mesmos últimos 250 anos - o Estado-Nação -

\footnotetext{
${ }^{8}$ VIZENTINI, Paulo Fagundes. Política de Defesa e Segurança do Brasil para o Século XXI: soberania, questão amazônica e integração sul-americana. In: FERNANDES, Luis \& REBELO, Aldo. Política de Defesa para o Século XXI. Brasília: Câmara dos Deputados, Coordenação de Publicações, 2003. P. 255-257.

${ }^{9}$ VIZENTINI, Paulo Fagundes. O Brasil e a Integração SulAmericana: força e fragilidade de um gigante periférico. In: VIZENTINI, Paulo Fagundes \& WIESERBRON, Marianne (orgs.). Neohegemonia americana ou multipolaridade? Porto Alegre: Editora da UFRGS, 2006. Ver também a inclusão possível dos modelos de integração que sejam baseados em liberalização em MITTELMAN, James H. The Globalization Syndrome. EUA: Princeton University Press, 2000. P. 127.
} 
chegaria a um nível de debilidade quase derradeiro, mantendo-se apenas em uma esfera de competências que agiria em complementaridade à preponderância das novas instâncias. $O$ que restaria então para o mundo do século XXI seria a emergência dos "Estados-regiões" como referências deliberativas da economia e da política global para um mundo que pretensamente não teria - ou não deveria ter nesta pretensão fronteiras. Aqui se encontra uma contribuição que pode não se alavancar através de chaves teóricas substantivas, mas que propõe um esquema liberal para a regionalização ${ }^{10}$. Talvez o maior problema de Ohmae seja não pontuar criticamente os problemas de segurança envolvendo a abrupta ruptura da validez do Estado-Nação nas suas faculdades constitutivas aplicadas, bem como o próprio interesse das elites nacionais (abastadas ou menos abastadas) em manter-se unidos em torno de um projeto de país, além de não ter percebido que a instância nacional persiste conquanto desenrolem-se tensões no sistema internacional de Estados. Cabe comentar que, apesar disso, Ohmae aponta dentro da sua notada objetividade uma solução razoável para a observação geral acerca da dúvida se serão esses Estado-Nações os verdadeiros protagonistas da atual economia global e sobre quais seriam exatamente as unidades de negócios naturais através das quais se integram nessa economia. Envolvido incidentalmente na exagerada tendência do final do milênio passado em vislumbrar o fim do Estado-

\footnotetext{
${ }^{10}$ Ver: OHMAE, Kenichi. O fim do Estado-Nação. Rio de Janeiro: Campus, 1996. Para uma crítica avançada acerca desta leitura, sugerimos contraposta contribuição em CORREA, Rafael. Introducción: el sofisma del libre comercio. In: ACOSTA, Alberto et al. El rostro oculto del TLC. Quito: Abya-Yala, 2006.
}

Nação enquanto paradigma para as questões ao seu tempo concernentes, Ohmae acerta rapidamente ao crer que o mundo se transformou e que a economia global norteará em grande medida a nova e indisciplinada realidade contemporânea, apesar do seu modelo ser duramente abalroado pelos nacionalismos em franca ascensão e aos novos movimentos políticos altermundialistas revigorados no século XXI, ulterior. Mas, nesta lógica por ele sugerida, a nova natureza dos fluxos globais (segundo ele o "gênio que está fora da garrafa") indicaria quiçá acertadamente - que nenhuma dos modelos de arranjo nascidos na modernidade - linha de política familiar, estratégia tradicional e formas arraigadas de organização - se manteriam estáveis e funcionais o suficiente para permanecer viva.

A questão é que o Estado-Nação parido na modernidade se manteve mais forte do que imaginou Ohmae, e na América do Sul compõe na soma das partes o todo da integração dos povos sul-americanos através da composição somatória dos projetos de desenvolvimento nacional popular derivando em um possível projeto de desenvolvimento regional, nos termos de Hélio Jaguaribe ${ }^{11}$. E o regionalismo, cujo declínio teórico e prático ocorreu ao longo da década de '70, ganhou força de forma impressionante ao longo dos anos ' 80 e se transformou, nos últimos 20 anos, em uma tendência praticamente majoritária e singular no seu percurso histórico, firmando seu lugar ao sol nas políticas externas dos mais variados portes e tipos de Estado ${ }^{12}$. Essa realização de um projeto de integração e

\footnotetext{
${ }^{11}$ Ver o prefácio de Helio Jaguaribe em GULLO, Marcelo. Argentina-Brasil: a grande oportunidade. Trad. Glória Rodríguez. Rio de Janeiro: Mauad, 2006.

${ }^{12}$ MITTELMAN, Ibidem, P. 111.
} 
desenvolvimento regional, como mencionou Jaguaribe, só foi possível em função de um variado leque de iniciativas dos governos sul-americanos, buscando desvelar modos e formas de união entre os países para comungar de modelos convergentes de superação da condição de atraso. Para uma compreensão mais clara sobre o tempo presente, nos voltamos a um tempo pouco anterior ao nosso recorte - para um período contíguo ao último quartel do século $\mathrm{XX}$, mais detalhadamente ao início do fim da Guerra Fria (1946-1991), com o reaquecimento do conflito - a Segunda Guerra Fria (1979-1989), segundo periodização sugerida por Fred Halliday ${ }^{13}$ - quando se prosseguiu na direção do mundo no qual tais transformações e esforços hoje viventes começaram a se constituir para o atual entendimento sobre a importância da América do Sul para o Brasil. É no mundo do fim da Guerra Fria que se desenrola a preeminência do doutrinário esquemático neoliberal, da hiperpotência estadunidense, do reposicionamento brasileiro no mundo e da retomada dos projetos nacionais de desenvolvimento no alvorecer do Século XXI.

\section{UM QUADRO HISTÓRICO DE PROGRES- SÕES}

Tais esforços caminham nas continuidades e descontinuidades das décadas anteriores, na qual podemos e devemos localizar a gênese de tais iniciativas. Ainda no período imediato à Segunda Guerra Fria, os governos brasileiro e argentino, respectivamente chefiados em regime de exceção por João Batista Figueiredo (1979-1985) e Jorge

\footnotetext{
${ }^{13}$ HALLIDAY, F. The making of the Second Cold War. London: Verso, 1983.
}

Rafael Videla (1976-1981) mudam a direção das animosidades da década de '70, na qual - Brasil já havia diversificado suas parcerias de forma pragmática ${ }^{14}$ e avançado na direção da maior amplitude de conveniências internacionais sobre a plataforma subcontinental, como na assinatura do Tratado de Cooperação Amazônico de $1978{ }^{15}$. Em momento difícil do sistema internacional para países emergentes médios como o Brasil - era um tempo de Crise da Dívida Externa e da ascensão definitiva do neoliberalismo - os presidentes avançam no desenvolvimento de aparatos para a integração, posteriormente basilares para os progressos na integração bilateral entre as duas maiores economias e geografias sulamericanas: o Acordo de Cooperação entre o Governo da República Federativa do Brasil e o Governo da República Argentina para o Desenvolvimento e Aplicação dos Usos Pacíficos da Energia Nuclear, de maio de 1980. Cabe frisar que, antes, em 1979, foram es-

\footnotetext{
${ }^{14}$ Ver SPEKTOR, Matias (Org.). Azeredo da Silveira: um depoimento. Rio de Janeiro: Editora da FGV, 2010; SPEKTOR, Matias. Ruptura e Legado: o colapso da Cordialidade Oficial e a construção da parceria entre Brasil e Argentina. Dissertação apresentada como requisito parcial à obtenção do grau de Mestre em Relações Internacionais. Universidade de Brasília, Instituto de Relações Internacionais, 2002. Ver também: BANDEIRA, Luiz. Alberto Moniz. O eixo Argentina-Brasil: o processo de integração da América Latina. Brasília: Universidade de Brasília, 1987; Estado nacional e política internacional na América Latina: o continente nas relações Argentina-Brasil, 1930-1992. 2. ed. Brasília: Universidade de Brasília e Ensaio, 1995; BARROS, A. S. C. The diplomacy of national security: South American international relations in a defrosting world. In: Helmah, R. G.; Ronsenbaum, H. J. (Eds.) Latin America: the search for a new international role, [S.I: s.n.], [19--?]. p. 131-150.

${ }^{15}$ FERRIS, Elizabeth G. The Andean Pact and the Amazon Treaty: Reflections of Changing Latin American Relations. Journal of Interamerican Studies and World Affairs, Vol. 23, No. 2. Maio de 1981.
} 
tas presidências que também assinaram o Acordo de Cooperação para o aproveitamento hidrelétrico das usinas de Itaipu e Corpus Christi. Assim sendo, é possível apontar, aí, uma veia de compreensão sobre a gênese das referências atuais e dos pontos fundantes da institucionalidade orientada em torno do MERCOSUL. Ao longo dessa década, em meio às redemocratizações, avançar-se-ia no estabelecimento, ainda que com problemas estruturais, dos nexos basilares para uma emergente comunidade de segurança sul-americana ${ }^{16}$. A questão Argentina-Brasil, outrora rivalista e impenetrável, cedeu espaço à aspiração de relações mais próximas, como diagnosticaram prospecções acadêmicas e análises profundas sobre o novo molde pensado a partir dos anos '80. Buscou-se (e ainda se projetam) intentos para vencer os persistentes desafios da "ação política e culturalideológica da Inglaterra e Estados Unidos, a herança da rivalidade entre a Espanha e Portugal e o desconhecimento mútuo" ${ }^{17}$. a questão da "segurança real de que os membros da comunidade não irão se agredir fisicamente, mas vão dar margem as suas disputas de uma outra forma" se torna uma perspectiva mais sólida (2).

A própria assinatura do Tratado de Ouro Preto, em 1991, pelos presidentes da Argentina, Brasil, Paraguai e Uruguai, firmando a confirmação do Mercado Comum do Sul (MERCOSUL) seria o ponto alto desta agenda.

\footnotetext{
${ }^{16}$ HURRELL, Andrew. An emerging security community in South America? In: GOLDSTEIN, J.; KEOHANE, R. Ideas and foreign policy: beliefs,institutions and political change. EUA: Cornell University Press, 1998.

17 GULLO, op. cit. p.92. Ver ainda: SANTORO, Mauricio. Saindo do Dilema: a cooperação Brasil-Argentina à luz da Teoria dos Jogos. Revista Nunciopolítica, Barbacena - MG, v. 1, p. 1-10, 2004.
}

Pode-se notar, outrossim, que a gestão da questão energética e políticoinstitucional entre as principais potências regionais, bem como na relação multilateral entre Brasil e seus vizinhos ao norte do subcontinente, esteve franqueada ao mais alto nível das prioridades da nossa política externa. Em 1980, o presidente Figueiredo discursou na cerimônia de encerramento da I Reunião dos Ministros das Relações Exteriores dos Países Signatários do Tratado de Cooperação da Amazônia, em Belém do Pará. Na ocasião, esses países - Brasil, Colômbia, Venezuela, Peru, Equador, Bolívia, Guiana e Suriname - assinaram a Declaração de Belém, afiançando que o uso dos recursos naturais nos territórios nacionais de forma "soberana e exclusiva" ${ }^{18}$, o que nos indica a recorrente preocupação acerca do invólucro ambiental, energética e fronteiriça da Amazônia durante o regime civilmilitar (1964-1985).

Tudo isto ocorre, como mencionamos, no contexto residual das crises do petróleo década de '70, na qual o aumento do preço do petróleo trouxe vitalidade e potencial de uso e comércio para as energias hidrelétrica e gasífera - tratam-se de duas matrizes nativas na nossa região, as quais possuíam perspectivas promissoras em manancial para a sua exploração. Anos após o investimento massivo realizado entre 1975-1982 (construção de Itaipu) e 1996-1999 (construção do Gasoduto Brasil-Bolívia), ambas foram motivos de fortes questionamentos sociais nos países onde tais reservas encontram-se armazenadas ou inutilizadas, questão que trataremos posteriormente. De to-

\footnotetext{
${ }^{18}$ Diário Oficial da União (DOU) de 29/12/1980, Página 21, Seção 1. Disponível em: <www.jusbrasil.com.br/dia rios/3555125/dou-secao-1-29-12-1980-pg-21>. Acesso em 13 mar. 2012.
} 
da maneira, as caracterizações mais relevantes no entendimento analítico das deficiências, questões e necessidades em torno dos mecanismos de exploração convergem para a mais clara e eficiente securitização da oferta de suprimentos energéticos. E nesse sentido, securitização tem a ver com confiabilidade plena sobre o retorno dos investimentos e, ainda, sobre custos operacionais reduzidos para os sistemas nacionais reunidos em torno de grandes centros de concentração convergente de potencial multimatriz em energia ${ }^{19}$.

Ou seja, à guisa de exemplo no Cone Sul - exploraremos tais convergências em outras regiões sul-americanas mais adiante -, podemos aqui demonstrar que a logística da convergência infraestrutural de energia baseada nas matrizes 'limpas' do subcontinente tem fundamento prático e aplicável, especialmente quando relacionada às cadeias de comércio intrabloco manifestas na região: neste anel e suas adjacências contíguas, podemos claramente referenciar e elencar algumas das principais cidades (Buenos Aires, Porto Alegre, Montevideo, Rio de Janeiro, Rosario, Santa Cruz de La Sierra, entre outras) e as suas rotas de comércio derivadas da sua existência. Igualmente, é preciso mencionar a sua coincidente presença no mesmo plano geográfico do Eixo de Capricórnio, da Iniciativa para a Integração da Infraestrutura Regional SulAmericana (IIRSA). Ainda, é necessário incluir tal discussão no âmbito do projeto de expansão bioceânica do Brasil na direção do Oceano Pacífico. Assim sendo, nos inclinaremos também sobre a discussão das atuais

${ }^{19}$ DE OLIVEIRA, Adilson. Segurança energética no Cone Sul. In: CADERNOS ADENAUER VI. Energia: da crise aos conflitos? Rio de Janeiro: Fundação Konrad Adenauer, 2005. P. 78. possibilidades de infraestrutura rodoviária mais adiante, observáveis nas próximas páginas.

É impossível falar do projeto de regionalização sul-americano entre 2002 e 2012 sem mencionar a IIRSA, projeto que converge os interesses e iniciativas de doze países sul-americanos com o objetivo de promover o "desenvolvimento da infraestrutura de transporte, energia e comunicação (...) através da integração física destes países" ${ }^{20}$. Baseada em princípios orientados pelo regionalismo aberto, pela integração através do desenvolvimento de faixas multinacionais de concentração do comércio e indústria, pela ampliação do valor agregado na produção de bens e serviços, na convergência normativa e na coordenação público privada, a IIRSA se organiza em torno de dez eixos - os chamados EID, Eixos de Integração e Desenvolvimento. A saber: Andino, do Amazonas, Peru-Brasil-Bolívia, Capricórnio, Escudo Guianês, Andino do Sul, Interoceânico Central, MERCOSUL-Chile, Hidrovia Paraná-Paraguai e do Sul. A IIRSA se materializa no Brasil em setembro de $2001^{21}$, ainda no governo Fernando Henrique Cardoso (1994-2001), e acumula uma carteira de 514 projetos cujo custo total orbita em torno de US\$ 86 bilhões. O mecanismo de acesso a esta carteira de projetos, passando pela faixa orçamentária, a

\footnotetext{
${ }^{20}$ MINISTÉRIO DO PLANEJAMENTO, ORÇAMENTO E GESTÃO. Iniciativa para a Integração da Infraestrutura Regional Sul-Americana (IIRSA). Disponível em: $<w w w$. planejamento.gov.br/secretaria.asp?cat $=156 \&$ s $u b=302 \&$ sec $=10>$. Acesso em 20 dez 2011.

${ }^{21}$ Ver: PRESIDÊNCIA DA REPÚBLICA - SUBCHEFIA PARA ASSUNTOS JURÍDICOS. Decreto de 17 de Setembro de 2001, que cria a Comissão Interministerial para a Integração da Infra-Estrutura Regional da América do Sul, com a finalidade de articular as ações de governo nessa área. Disponível em: <www.planalto.gov.br/ccivil_03/ DNN/2001/Dnn9324.htm>. Acesso em 19 maio 2011.
} 
área, os países envolvidos e dados afins ganharam tons de transparência considerável ao longo dos últimos anos, em especial em 2012, quando o portal de acesso às informações foi profundamente reestruturado para oferecer subsídios para a consulta pública a tais informações. Segundo o link de referência no portal do Ministério do Planejamento, Orçamento e Gestão do Brasil, "Entre todos os projetos que compõem a carteira da IIRSA, 31 deles fazem parte da denominada Agenda de Implementação Consensual (AIC) 2005-2010, sendo considerados como prioritários a partir da validação dos países participantes. Deste total, 9 (nove) estão sob a responsabilidade ou têm participação do Brasil".

\section{CONCLUSÕES POSSÍVEIS SOBRE UM PAS- SADO RECENTE}

Todos estes dados, em corte histórico, demonstram a relevância da IIRSA como projeto de destaque e retomada do desenvolvimento pela infraestrutura na América do Sul em um momento crucial da história do subcontinente: em plena virada do milênio, em uma era socialmente sensível e com mudanças políticas disruptivas na América do Sul, o que imediatamente justifica qualquer papel de destaque a ser colocado em questão na análise sobre a IIRSA. Em outras e mais simples palavras, a IIRSA teve papel histórico efetivo e simbólico no projeto de integração regional sul-americana no amanhecer do Século XXI, como seus números e críticas antagônicas ou construtivas demonstram. No entanto, uma contundente questão deve ser colocada à mesa para a compreensão - já histórica - sobre a IIRSA. Com base nos balanços de dez anos de pregnância e eficácia da IIRSA, aponta-se que boa parte das nações passou por mudanças sócio-econômicas e políticas, reestruturando seus agentes de fomento. Ainda, pela própria desconexão com as outras formas institucionais organizadas em torno do projeto de integração - a IIRSA, de fato, não possuía clara conexão com os problemas dos desenvolvimentos ambientais e sociais do subcontinente - e, por fim, a própria institucionalidade crescente e cada dia mais relevante da União das Nações SulAmericanas acabaram por colocar a IIRSA em xeque de forma quase definitiva quando tratada como protagonista do processo.

Com base na análise do Banco Interamericano de Desenvolvimento, A proposta do relatório era que o BID deixasse de participar da Iniciativa em 2010, discutia-se que " $a$ IIRSA não vinha tendo um papel de destaque na agenda de integração em construção na América do Sul. O que estava posto em xeque era a relevância da IIRSA no contexto de prioridades políticas em mudança no subcontinente, até porque, segundo o autor, as origens neoliberais da Iniciativa não coadunavam com o momento político da América do Sul." ${ }^{22}$. No âmbito da própria UNASUL, o Conselho de Infraestrutura e Planejamento (COSIPLAN) suplantou a capacidade da IIRSA em gestão e fez com que a IIRSA tornasse, apenas, uma antessala técnica para os temas da integração física.

\footnotetext{
${ }^{22}$ VITTE, Claudete de Castro Silva. Integração da Infraestrutura produtiva e ordenamento territorial na América do Sul: geoeconomia e política externa brasileira como condicionantes. XIV Encontro Nacional da ANPUR. Rio de Janeiro, 2011. Ver também: BECKER, Bertha et al. (orgs.). Dimensões humanas da biosfera-atmosfera na Amazônia.São Paulo: Edusp, 2007; McELHINY, Vince. A IIRSA em uma encruzilhada: indicativos de mudança, implicações para a advocacy. In: VERDUN, Ricardo et alii (orgs.). Financiamento e megaprojetos: Uma interpretação da dinâmica regional sul-americana. Brasília: Inesc, 2008.
} 
O COSIPLAN foi preparado como projeto em agosto de 2009, no momento da reunião da UNASUL, quando foi decidida a substituição do Comitê Diretivo da IIRSA por um ConseIho de Ministros capacitado no mais alto nível da estrutura da União de nações. $\mathrm{Na}$ sua ascendente rotina de trabalho, a Agenda de Projetos Prioritários de Integração (API) é o efeito do esforço do ano de 2011, consolidado pelos 12 países na esfera do COSIPLAN, gerando um conjunto de 31 projetos por um investimento estimado em US\$13 bilhões, de alto impacto para a integração física, em caráter estratégico. Com segurança, o Plano de Ação Estratégico (PAE) 2012-2022 do COSIPLAN será determinante para a compreensão futura do projeto regional visto pelo viés da integração física. O próprio PAE, em consonância com o reconhecimento histórico sobre a IIRSA, assinala que a metodologia de planejamento territorial e a constituição de mecanismos consensuais de variado e diverso alto nível são pontos relevantes e méritos para considerar-se a IIRSA um marco histórico ${ }^{23}$. É preciso que vejamos, neste documento de suma importância, o reconhecimento sobre os antecedentes da IIRSA: o Portfólio de Projetos IIRSA (2004-2010) e a Agenda de Implementação Consensuada (AIC) de 2005-2010.

Ainda que neste sentido devamos destacar e reforçar o papel histórico da IIRSA, historicamente demarcado, é preciso reposicionar as nossas instituições na direção de

\footnotetext{
${ }^{23}$ UNIÃO DAS NAÇÕES SUL-AMERICANAS/CONSELHO SUL-AMERICANO DE INFRAESTRUTURA E PLANEJAMENTO. API - Agenda de projetos prioritários de integração. Disponível em: <www.planejamento.gov.br/ secretarias/upload/Arquivos/noticias/spi/111130_Cosi plan_API_Agenda_de_projetos_prioritarios_de_integra cao.pdf>. Acesso em 09 maio 2012.
}

um novo olhar sobre as novas e autônomas formas institucionais da regionalização sulamericana. A UNASUL, neste sentido, representou efetivo passo à frente e o COSIPLAN, no que se refere a integração física, representará a sua vanguarda. 